CIENCIAMATRIA

Revista Interdisciplinaria de Humanidades, Educación, Ciencia y Tecnología

Año VII. Vol. VII. N¹2. Enero - Junio. 2021

Hecho el depósito de ley: pp201602FA4721

ISSN-L: 2542-3029; ISSN: 2610-802X

Universidad Nacional Experimental Francisco de Miranda (UNEFM). Santa Ana de Coro. Venezuela

Lenys Piña-Ferrer

DOI $10.35381 / \mathrm{cm} . v 7 i 12.456$

\title{
Cambios ontoepistemológicos de las Ciencias Administrativas ante el nuevo contexto laboral producto de la pandemia
}

La crisis que vive la humanidad hoy día producto de la pandemia Covid 19, ha venido ocasionando grandes cambios en los individuos en todas las disciplinas, incluso en el ámbito laboral, todo ello ha incrementado una gran cantidad de elementos estresores que han hecho que las jornadas de trabajo no sean las más productivas posibles. Sin embargo, a pesar de todos los esfuerzos realizados por los gerentes de diversas empresas ante esta situación, los efectos en las personas cada vez se han ido siendo más visibles.

A pesar de que algunos de estos elementos estresores datan de años anteriores, hoy día se han acentuado y traído consecuencias entre ellos el exceso de carga laboral, el burnout, la ansiedad, el estrés, los cambios de horarios, las personas se notan más vulnerables, es decir a pesar de la información recibida por las redes en cuanto al Covid 19 , al parecer no es suficiente para evitar que en los individuos se generen este tipo de cambios.

De hecho, se ha tenido que pasar y precipitar algunas tendencias como por ejemplo lo relacionado a las tecnologías, a pesar de que hoy día es una de las respuestas más efectivas en las organizaciones laborales, también es importante resaltar que no todos los miembros de las organizaciones tienen las competencias técnicas para desarrollarse en ellas, aquí surge el teletrabajo como una de las opciones más beneficiosas para los profesionales de diferentes áreas del campo laboral.

Sin embargo, ante todos estos ajustes es importante preguntarnos. ¿Serán suficientes estas alternativas para la productividad y calidad laboral de las organizaciones? ¿Cómo quedan los cambios desde el contexto ontoepistemológico en los individuos? ¿Acaso no se verán afectados para poder tener un buen desempeño? Incluso a pesar de tener años trabajando en una organización.

En razón de lo anterior se hace necesario que en las organizaciones se estudie la forma en que el ser humano actúa de manera consciente o inconscientemente para poder adquirir o concebir los respectivos conocimientos que a bien tenga en las diferentes áreas del contexto administrativo, es necesario hacer una mirada al enfoque desde la perspectiva no sólo cuantitativa que busca la medición de los fenómenos sociales para poder analizar las diferentes variables, sino también los aspectos cualitativos que son todos aquellos que estudian los fenómenos sociales, es decir hacer el estudio donde se considere el objeto social de manera holística y así poder desde esta proyección buscar los resultados esperados.

Los nuevos enfoques gerenciales, ante estos cambios suscitados deben dar un vuelco a diversas posibilidades de gestión, y deben enfrentarse a nuevos retos en la gerencia, allí surge lo que se denomina hoy día enfoques gerenciales emergentes que son aquellos 


\section{CIENCIAMATRIA}

Revista Interdisciplinaria de Humanidades, Educación, Ciencia y Tecnología

Año VII. Vol. VII. N¹2. Enero - Junio. 2021

Hecho el depósito de ley: pp201602FA4721

ISSN-L: 2542-3029; ISSN: 2610-802X

Universidad Nacional Experimental Francisco de Miranda (UNEFM). Santa Ana de Coro. Venezuela

Lenys Piña-Ferrer

que le permiten a los miembros de una organización transformar esos pensamientos gerenciales y poderse adaptarlos a las actuales realidades del contexto global de la sociedad hoy día, que en el caso particular va referido a la pandemia del Covid 19. En ese sentido, sólo los gerentes que perciban la complejidad de los procesos administrativos podrán alcanzar y entender la concurrencia de la complementariedad y las diversas contradicciones que pueden surgir en las organizaciones que dirigen y así poder articular desde diferentes aristas el proceso gerencial dentro de un clima organizacional cónsono y agradable con todos los miembros del equipo.

Dra. Lenys Piña-Ferrer

lenyspina@iieakoinonia.org

Instituto de Investigación y Estudios Avanzados Koinonía, Santa Ana de Coro

Venezuela

https://orcid.org/0000-0002-9493-7499 